\title{
ILUMINAÇÃO ARTIFICIAL APLICADA À ARQUITETURA: PROCESSO DE PROJETO
}

\section{ARTIFICIAL LIGHTING APPLIED TO ARCHITECTURE:} DESIGN PROCESS

\section{Fernanda Brito Bandeira', Paulo Sergio Scarazzato ${ }^{1}$}

RESUMO: O processo de projeto, com todos os elementos que o caracterizam, é responsável pela qualidade do projeto como um todo. No Brasil, no caso de projetos de iluminação para edificações, pouco se discute sobre o seu processo de projeto, apesar do aumento de cursos de pós-graduação nesta subárea da arquitetura na última década. Este artigo apresenta alguns aspectos que, atualmente, são considerados no processo de projeto de iluminação artificial aplicado à arquitetura, segundo o entendimento de projetistas especialistas que dedicam sua atuação profissional majoritariamente a projetos de iluminação. Os especialistas foram consultados por meio de questionário eletrônico, e as questões foram desenvolvidas a partir de revisão bibliográfica temática. Os elementos consultados foram as fases de projeto, ferramentas de apoio, conceitos de qualidade de iluminação e problemas enfrentados na rotina projetual. Na sequência, a fim de delinear o processo de projeto, os resultados foram analisados com base na compilação das respostas que indicaram as atividades profissionais. Além de identificar como se dá o processo de projeto dos participantes, as respostas dos questionários indicaram que algumas fases de projeto e variáveis de projeto preconizadas na literatura não são aplicadas na sua totalidade por todos os profissionais. Também foi identificada alta incidência de alguns problemas na rotina projetual.

PALAVRAS-CHAVE: Iluminação Artificial; Projeto de lluminação; Iluminação Aplicada à Arquitetura; Processo de Projeto; e-Questionário.

ABSTRACT: In the design process, each one of its constituent element influences the quality of the design as a whole. In Brazil, little has been discussed regarding building lighting design process, despite the growth of graduate courses in this sub-area of architectural studies in the last decade. This paper presents some aspects that are currently considered in the artificial lighting design process applied to architecture, according to the understanding of expert lighting designers. The experts were consulted through an electronic survey, and the questions were developed based on a thematic bibliographic review. The questions of the survey were about the design phases, support tools, lighting quality concepts and issues faced in the design routine. Then, to delineate the light designing process, the analysis of the results was based on the compilation of responses that showed the professional activities. Besides identifying how the participants' design process takes place, the survey responses indicated that some design phases and design variables recommended in the literature are not applied in their entirety by all professionals. It was also identified a high incidence of some common problems in the design routine.

KEYWORDS: Artificial Lighting; Lighting Design; Lighting Applied to Architecture; Design Process; e-Survey. 


\section{INTRODUÇÃO}

A luz tem grande influência no comportamento das pessoas, podendo tanto ajudar no desempenho cognitivo para a realização de uma tarefa qualquer (WANG; BOUBEKRI, 2011) como induzir à desatenção, que, por sua vez, pode ocasionar sérias consequências à integridade física. Os benefícios de uma boa iluminação são inegáveis, tanto na escala dos edifícios como na das cidades. Iluminação adequada não apenas contribui para a manutenção da saúde, como também pode ajudar a promovê-la (JONES; MILLER; ILLUMINATING ENGINEERING SOCIETY OF NORTH AMERICA, 2008). A luz pode ser repousante ou estimulante e, nos dois casos, ela é imprescindível para o equilíbrio do humor e para o bem-estar (BARON; REA; DANIELS, 1992). Dessa forma, a depender das exigências do projeto, todos os elementos subjetivos supracitados devem ser considerados no desenvolvimento de soluções com a mesma significância de elementos quantitativos.

A Associação Brasileira de Normas Técnicas (ABNT), por meio da NBR ISO/ CIE 8995-11', destaca, dentre outros conceitos, os "requisitos para o planejamento da iluminação" para arquitetura. São eles: atividade do ambiente; iluminância mantida; índice limite de ofuscamento unificado; e índice de reprodução de cor (ASSOCIAÇÃO BRASILEIRA DE NORMAS TÉCNICAS, 2013). Apesar da importância e necessidade de normas técnicas, importa observar que elas são pensadas para expressar princípios gerais, com o objetivo de evitar iluminação inapropriada (BOYCE; SMET, 2014). Portanto, normas não podem garantir a qualidade do projeto, no qual se encontra uma série complexa de parâmetros qualitativos e quantitativos. Desse modo, compete ao especialista em iluminação interpretar e concatenar essas diretrizes para uma iluminação apropriada (REA; ILLUMINATING ENGINEERING SOCIETY OF NORTH AMERICA, 2000). Assim sendo, para alcançar bons resultados nos aspectos supracitados, o especialista precisa ter a capacidade de aplicar, em seus projetos, conceitos normativos, técnicos e estéticos que promovam o bem-estar e respeitem 0 meio ambiente (ABOUT LIGHTING..., [201-?]).

O projeto de iluminação aplicado à arquitetura tende a ser usualmente desenvolvido por arquitetos, designers de produto, designers de interiores, iluminadores cênicos, engenheiros eletricistas e civis, bem como fabricantes de luminárias (DILAURA; ILLUMINATING ENGINEERING SOCIETY, 2011; OLIVEIRA, 2012). Segundo Toledo (2008), nos cursos de graduação em arquitetura oferecidos no Brasil, questões sobre iluminação costumam ser abordadas em duas frentes, dirigidas à iluminação artificial e à natural. Toledo (2008) também observa que os especialistas em iluminação muitas vezes são chamados em etapas avançadas do projeto de arquitetura, com prejuízo para o desenvolvimento compartilhado do projeto e, consequentemente, com subaproveitamento do potencial da iluminação natural.

Brandston (2012) observa que, enquanto temas como "aquecimento global" e "sustentabilidade" são recorrentes na política e na mídia, o mesmo não ocorre com questões de iluminação, apesar da sua importância nos dois temas citados. Ainda assim, é constante a ideia de que problemas relacionados ao uso racional de energia serão solucionados através da iluminação.

Segundo o cadastro e-MEC de instituições e cursos de educação superior, a primeira pós-graduação da área foi cadastrada em 2009. Nesse cadastro, são oferecidos 21 cursos de pós-graduação de iluminação ${ }^{2}$ relacionada a arquitetura, com média de 420 horas de aulas, presente nas cinco regiões do país ${ }^{3}$. Tais dados denotam aumento no interesse por cursos de iluminação.

Portanto, com o entusiasmo crescente pela iluminação - seja pelo reconhecimento de sua importância nas atividades humanas, seja por sua caracterização como especialidade -, aumenta a demanda por projetos de

"Esta norma é uma adoção idêntica, em conteúdo técnico, estrutura e redação, à ISO/CIE 8995-1:2002 e Cor 1:2005, que foi elaborada conjuntamente pelo CIE-TC e ISO/TC 159" (ASSOCIAÇÃO BRASILEIRA DE NORMAS TÉCNICAS, 2013, p. 6)

Foram consideradas pós-graduações que, em seus títulos, continham as palavras ou termos "iluminação", "arquitetura de iluminação", "lighting” ou "lighting design” (http://emec.mec.gov.br/).

Essa busca foi realizada no site <http://emec.mec.gov.br/>, na ferramenta "consulta avançada". 
iluminação aplicados à arquitetura. Como consequência, surge também o interesse por entender o processo de projeto de modo a fomentar melhorias no desenvolvimento desses projetos.

$\mathrm{Na}$ arquitetura, métodos de projeto vêm sendo estudados de modo sistematizado desde a década de 1960, com especial valorização de metodologias que permitem um processo de projeto mais consciente e, assim, menos intuitivo (KOWALTOWSKI; BIANCHI; PETRECHE, 2011). Tal preocupação é importante, pois informações referentes à aplicação de estratégias e ferramentas e ao uso de parâmetros para auxiliar o processo de projeto são essenciais, haja vista que a tarefa de projetar arquitetura é uma atividade complexa com inúmeras variáveis (KOWALTOWSKI; BIANCHI; PETRECHE, 2011). No entanto, sobre iluminação, é enorme a dificuldade em encontrar informações sistematizadas sobre como se dá o processo em projetos. As informações mais difundidas sobre iluminação se referem a aspectos quantitativos e normativos em geral e à apresentação comentada de projetos realizados em revistas da área.

Buscas realizadas pelos autores em bases de dados ${ }^{4}$ demonstraram que, embora existam muitas linhas de pesquisa em iluminação, pouco se discutiu até agora sobre o processo de projeto ${ }^{5}$. Assim, este artigo se propõe a levantar, de forma sistemática, aspectos sobre o processo de projeto em iluminação. As informações de interesse foram colhidas por meio de aplicação de questionário, baseado principalmente nas recomendações sobre qualidade de iluminação ${ }^{6}$ elencadas no livro $A$ guide to designing quality lighting for people and buildings (JONES; MILLER; ILLUMINATING ENGINEERING SOCIETY OF NORTH AMERICA, 2008) e nas fases de projeto comumente aplicadas no desenvolvimento de projetos de arquitetura.

\section{Qualidade de iluminação e fases de projeto}

Para compreensão acerca da qualidade do projeto em iluminação, este artigo tomou como referência principal a recomendação da Illuminating Engineering Society of North America (IES), segundo a qual, a qualidade é resultante da conjugação de fatores humanos, econômicos, energéticos e ambientais associados à arquitetura, (JONES; MILLER; ILLUMINATING ENGINEERING SOCIETY OF NORTH AMERICA, 2008). Embora diferentes abordagens da iluminação sejam possíveis, o grande desafio para o design de iluminação é conciliar as variáveis de projeto pertencentes a cada um dos três círculos da Figura 1, que não deve ser entendida como fechada em si mesma, mas passível de arranjos, inclusões e mesmo exclusões de itens, a depender da complexidade do projeto.

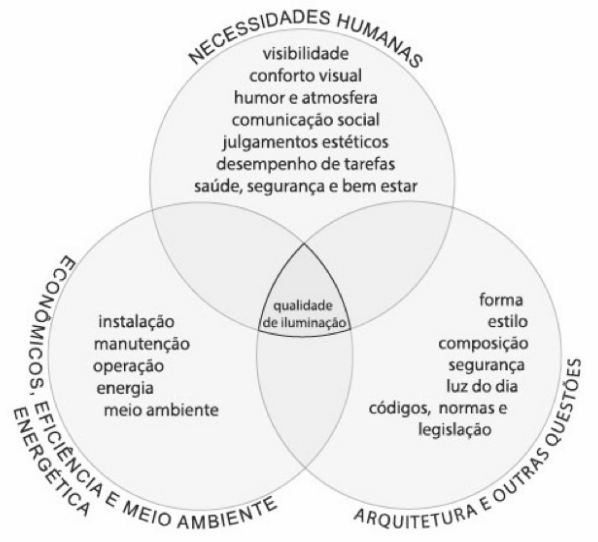

Vinculadas ao "Portal de Periódicos Capes/MEC” (http://www.periodicos.capes.gov.br/).

Foram pesquisados em 22 de janeiro de 2017, com auxílio de truncamento e operadores booleanos: projeto de iluminação; projeto luminotécnico; projetista de iluminação; processo de projeto; metodologia de projeto; dentre outros, também em língua inglesa.

Tradução livre feita pelos autores a partir do termo original, lighting quality.
Figura 1: Qualidade de iluminação: interseção das necessidades humanas, aspectos econômicos e ambientais, arquitetura e outras questões

Fonte: Adaptado de Jones, Miller \& Illuminating Engineering Society of North America, 2008. 
Como ocorre com outros tipos de projetos, o design de iluminação também é desenvolvido em fases. A partir de uma visão macro, é possível resumi-las em pré-projetação, projetação e pós-projetação (ROMANO, 2006). Por abordar iluminação aplicada à arquitetura, também é possível tomar como referência as fases de projeto de arquitetura definidas pela NBR 13532 (ASSOCIAÇÃO BRASILEIRA DE NORMAS TÉCNICAS, 1995). Já sob um ponto de vista mais específico, o Manual de escopo de serviços e projetos luminotécnicos, editado pela Associação Brasileira de Arquitetos de Iluminação (Asbai), sugere seis fases de desenvolvimento para o projeto de iluminação. Cada fase possui etapas recomendadas como essenciais, específicas ou opcionais a depender do escopo do projeto (ASSOCIAÇÃO BRASILEIRA DE ARQUITETOS DE ILUMINAÇÃO, 2000). Não há recomendações para questões projetuais. O manual da Asbai traz recomendações concernentes à documentação do processo e sugestões quanto aos produtos gerados. Desse modo, reunimos as fases preconizadas por Romano (2006), pela NBR 13532 (ASSOCIAÇÃO BRASILEIRA DE NORMAS TÉCNICAS, 1995) e pela Asbai (2000) no Quadro 1.

Quadro 1: Fases de projeto

\begin{tabular}{|c|c|c|}
\hline $\begin{array}{c}\text { Macrofases } \\
\text { Romano (2006) } \\
\end{array}$ & $\begin{array}{c}\text { Fases } \\
\text { ABNT (1995) } \\
\end{array}$ & $\begin{array}{c}\text { Fases } \\
\text { Asbai }(2000) \\
\end{array}$ \\
\hline Pré-projetação & $\begin{array}{l}\text { a) levantamento de dados } \\
\text { b) programa de necessidades } \\
\text { c) estudo de viabilidade }\end{array}$ & $\begin{array}{l}\text { Fase A: concepção do produto } \\
\text { Fase B: definição do produto }\end{array}$ \\
\hline Projetação & $\begin{array}{l}\text { d) estudo preliminar/ } \\
\text { anteprojeto } \\
\text { e) projeto executivo/ } \\
\text { detalhamento }\end{array}$ & $\begin{array}{c}\text { Fase C: identificação e solução de } \\
\text { interfaces } \\
\text { Fase D: detalhamento }\end{array}$ \\
\hline Pós-projetação & & $\begin{array}{l}\text { Fase E: pós-entrega do projeto } \\
\text { Fase F: pós-entrega da obra (ajustes } \\
\text { finos de posição de luminárias, como } \\
\text { focos, por exemplo; avaliação pós- } \\
\text { ocupação etc.) }\end{array}$ \\
\hline
\end{tabular}

Fonte: Adaptado de Romano (2006), Associação Brasileira de Normas Técnicas (1995) e Associação Brasileira de Arquitetos de lluminação (2000)

\section{OBJETIVOS}

\section{Objetivo geral}

Levantar aspectos que caracterizem o processo de projeto em iluminação artificial aplicado à arquitetura.

\section{Objetivo específico}

a) Consultar profissionais brasileiros especialistas em projeto de iluminação aplicada à arquitetura.

b) Identificar quais elementos do projeto de iluminação - como fases, ferramentas e variáveis de projeto - são, de fato, usados na prática profissional desses especialistas.

\section{MÉTODO}

O objeto deste artigo é compreender o processo de projeto de iluminação artificial para arquitetura. Logo, ficou claro que o melhor meio para entender como se dá tal processo seria consultar diretamente profissionais da área. Dessa forma, foi escolhida a aplicação de questionário estruturado para realizar pesquisa exploratória. Essa ferramenta é definida por Babbie (1999) como tipo de metodologia que coleta dados a partir de uma amostra e que tem por objetivo 
conhecer certa característica da população estudada. Foi escolhido o uso de questionário eletrônico ${ }^{7}$, aberto para todo o Brasil e destinado a profissionais que se consideram especialistas em iluminação. Essa solução on-line evita constranger os profissionais participantes, amplia o alcance da pesquisa e assegura o preenchimento independente entre os respondentes (GÜNTHER, 2003).

Contudo, dentre os questionários preenchidos, foram selecionados apenas profissionais que dedicam $80 \%$ ou mais das suas atividades profissionais a projetos de iluminação. Assim, a amostra, além de aleatória, é específica, constituída por profissionais especialistas ${ }^{8}$ e atuantes no mercado de projetos de iluminação (VOLPATO; BARRETO, 2016). Por se tratar de pesquisa descritiva, a análise e a discussão dos resultados são apresentadas de modo a exibir a tendência central dos dados (VOLPATO; BARRETO, 2016), de forma que os resultados permitam inferir o que faz parte ou não do processo de projeto dos projetistas participantes. A Figura 2 apresenta o resumo das definições referentes ao método. Destaca-se que o questionário coleta variáveis qualitativas e quantitativas da atividade profissional, uma vez que são elas que constituem o processo de projeto de iluminação. O próximo tópico deste artigo detalha a elaboração de todas as questões.

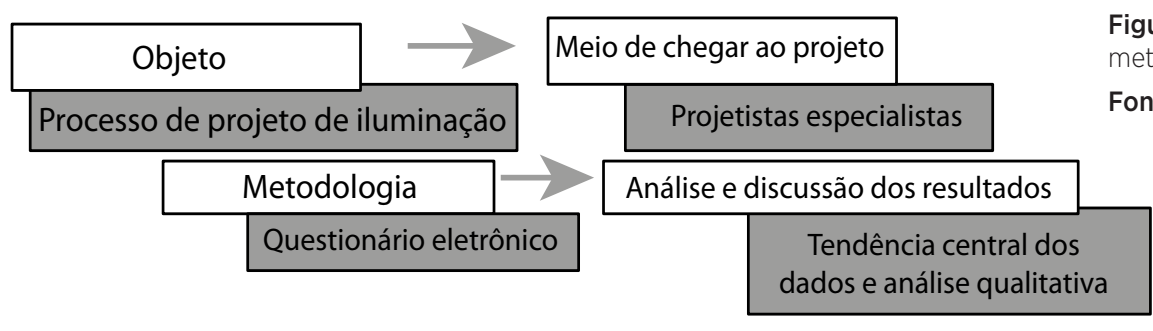

Figura 2: Esquema da metodologia

Fonte: Elaborada pelos autores

Outro detalhe a acrescentar ao método é a forma de contato com os profissionais: um endereço eletrônico (link) de acesso ao questionário foi enviado, seguido de breve resumo sobre os pesquisadores, a origem do questionário e seus objetivos. A participação não era obrigatória (GÜNTHER, 2003), baseada na justificativa do avanço na pesquisa sobre o tema. Tais informações foram enviadas para e-mails de entidades da área (solicitando que encaminhassem para seus associados/contatos) e divulgadas em grupos temáticos de arquitetura e iluminação nas redes sociais. A revista Lume Arquitetura ${ }^{9}$ também o compartilhou em sua página do Facebook e o enviou para seus contatos via e-mail. Esse trabalho de divulgação e coleta de dados aconteceu em fevereiro e março de 2017. A seguir, descreve-se a forma de divisão e apresentação do questionário, bem como a forma de elaboração das perguntas.

\section{Divisão do questionário: metodologia em dois blocos temáticos de perguntas}

O questionário foi organizado em dois blocos, do assunto mais geral para o mais específico de interesse (GÜNTHER, 2003). O primeiro bloco foi formado com duas questões destinadas à caracterização da amostra. $\mathrm{O}$ segundo, com quatro perguntas referentes ao processo de projeto adotado para projetos de iluminação, considerando: a) etapas de projeto; b) ferramentas utilizadas; c) variáveis de projeto consideradas; e d) dificuldades enfrentadas. Desse modo, as informações-chave da pesquisa foram colhidas nesse segundo bloco.

Em cada pergunta, foram incluídos campos de comentário, com o propósito de receber informação adicional, ou até mesmo de identificar alternativas faltantes na formulação da pergunta. Como a participação era voluntária, foi

A plataforma SurveyMonkey foi escolhida para elaborar o questionário e colher os dados, por ser gratuita para pesquisas de até dez questões.

Não se conhece a população de designers de iluminação no Brasil.

A revista Lume Arquitetura é referência na promoção da profissão de Lighting Designer. 
exigido, como condição sine qua non, que todas as questões fossem respondidas. Como garantia de privacidade e anonimato, foi assegurado aos participantes que nem mesmo os pesquisadores teriam como identificá-los. O tipo de cada pergunta - formulário, matriz, classificação -, foi definido conforme a característica da resposta almejada na questão.

A divisão em blocos e a preferência por questões com alternativas ou associações consideraram as recomendações de Dillmann (1974 apud GÜNTHER, 2003) de que a tarefa tem que ser facilitada ao respondente e reduzido o esforço físico e mental requerido, eliminando a possibilidade de embaraços. Os tópicos a seguir descrevem em detalhes a formulação das perguntas, por blocos temáticos, na mesma sequência e divisão que foram apresentadas aos respondentes.

Metodologia do bloco 1 de perguntas: caracterização da amostra (informações gerais do profissional/escritório respondente)

Esse bloco é composto de duas questões. A primeira foi desenvolvida como um formulário com respostas abertas, e objetivou colher os seguintes dados: a) percentual de atividades dedicadas à iluminação aplicada à arquitetura para confirmar se os respondentes atuam na área em questão ${ }^{10}$; b) ano de fundação do escritório; c) região geográfica; d) experiência profissional do projetista responsável em anos; e) composição da equipe ${ }^{11}$. Os assuntos abordados nos itens b), d) e e) foram baseados no questionário desenvolvido e utilizado por Deliberador (2010).

Para a questão seguinte, definiu-se como apropriado colher os dados com pergunta classificatória, de modo que as respostas fossem apresentadas no formato ranking. Essa parte identificou as tipologias que compõem o portfólio dos profissionais/escritórios, e quais delas são predominantes. As alternativas ${ }^{12}$ listadas foram: a) residencial; b) comercial; c) corporativo; d) hotelaria; e) educacional; f) institucional e/ou público. Com relação ao preenchimento, e em virtude de alguns profissionais/escritórios poderem trabalhar apenas com uma tipologia arquitetônica, foi determinado como obrigatório o preenchimento de um item (preenchimento parcial). A partir da escolha de duas tipologias, o respondente teve a obrigatoriedade de determinar qual sua posição no ranking, no qual 1 seria mais frequente e 6, menos frequente.

Metodologia do bloco 2 de perguntas: processo de projeto na rotina do escritório

Esse bloco é composto por quatro questões para abordar aspectos que caracterizem o processo de projeto. A primeira questão desse bloco foi desenvolvida no formato matriz para permitir a relação das afirmativas i) sim, ii) não ou iii) parcial, com as etapas: a) levantamento de dados; b) programa de necessidades; c) estudo de viabilidade; d) estudo preliminar/anteprojeto; e) projeto executivo/detalhamento; f) pós-entrega do projeto (avaliação pósocupação; ajustes finos de posição de luminárias e focos; etc.). Essa pergunta teve o propósito de identificar quais fases fazem parte da rotina projetual dos profissionais/escritórios, e as opções elencadas foram baseadas no Quadro 1.

Na sequência, a quarta pergunta do questionário referiu-se às ferramentas que auxiliam o processo de projeto. Solicitou-se ao respondente marcar: i) sim, ii) não ou iii) parcial para as seguintes alternativas: a) checklists; b) guias e manuais; c) software de representação e/ou simulação 3D; d) códigos, normas (ex.: NBR, ISO etc.), legislação e certificações (ex.: Procel Edifica, LEED etc.).

A quinta pergunta do questionário baseou-se no conceito de qualidade da iluminação proposto pela Illuminating Engineering Society of North America (ver Figura 1). Contudo, para fins de simplificação, as variáveis de projeto foram apresentadas de forma linear e contínua, não havendo

\footnotetext{
Assim, para a análise dos resultados, identificando e descartando questionários de projetistas que não se enquadrem nos objetivos da pesquisa.

Para identificar o porte do escritório.

As tipologias arquitetônicas listadas foram baseadas no mercado de atuação em arquitetura divulgado pelo primeiro Censo dos Arquitetos e Urbanistas do Brasil (CONSELHO DE ARQUITETURA E URBANISMO, 2012).
} 
separação definida entre as necessidades humanas, aspectos econômicos e ambientais, arquitetura e outras questões. E, assim como a questão anterior, foram apresentadas as afirmativas i) sim, ii) não ou iii) parcial, a serem relacionadas com as seguintes variáveis de projeto: a) estética; b) forma, estilo e composição; c) desempenho de tarefas; d) visibilidade e conforto visual; e) luz do dia; f) humor, atmosfera e comunicação social; g) segurança, saúde e bem-estar; h) consumo de energia; i) meio ambiente e sustentabilidade; j) instalação dos equipamentos/sistemas especificados; k) manutenção e operação dos equipamentos/sistema especificados.

A sexta e última questão solicitava ao respondente indicar a ocorrência das seguintes dificuldades enfrentadas ${ }^{13}$ na realidade profissional: a) interferências/ alterações não planejadas; b) recursos insuficientes para o escopo do projeto; c) projeto de iluminação contratado em fases avançadas do projeto de arquitetura; d) norma e legislação; e) dificuldade de acesso a publicações técnicas em virtude de idioma ou de recursos financeiros etc. A pergunta do tipo matriz permitiu relacionar cada item citado - de a) a e) - para uma das seguintes ocorrências: i) sempre; ii) frequentemente; iii) raramente; iv) nunca.

Por serem consideradas fundamentais para o entendimento do processo de projeto, foi solicitado resposta obrigatória em todas as linhas das matrizes de todas as questões do bloco 2.

\section{ANÁLISE E DISCUSSÃO DOS RESULTADOS}

O questionário foi respondido por 55 escritórios, dos quais 46 foram considerados válidos e 9 , inválidos -8 deles por não terem sido preenchidos totalmente e 1 por ter sido respondido por escritório que não exerce atividades no Brasil. Na sequência, em todos os questionários, o primeiro item analisado foi: "percentual das atividades do escritório dedicadas à iluminação". Como resultado, dos 46 respondentes, 20 indicaram que projetos de iluminação correspondem a até $79 \%$ de suas atividades, valor considerado como insuficiente para os objetivos da pesquisa e, logo, foram descartados. Assim, dos 46 questionários válidos, 26 foram analisados, e suas respostas, consideradas neste artigo. Como todos os respondentes são especialistas em iluminação aplicada à arquitetura e atuantes nesse mercado, foi considerado que a amostra é representativa para levantar aspectos gerais do todo e, assim, iniciar um estudo sobre o tema.

A seguir, a análise e discussão das seis questões do questionário são realizadas na mesma sequência em que o método foi apresentado. Dessa forma, os 26 questionários têm seus dados discutidos coletivamente, mas por assunto. A análise e discussão dos resultados apreciam a tendência central dos dados, de forma que a moda entre os respondentes é sempre destacada (VOLPATO; BARRETO, 2016). Com relação às variáveis, algumas são qualitativas e outras quantitativas, por exemplo, "região geográfica" e "quantidade de funcionários", respectivamente. Assim, informações gerais e a rotina de trabalho dos projetistas ajudam a delinear o processo de projeto por eles executado. Essas análises têm por fim contribuir de forma conceitual para ampliar a discussão no assunto, bem como apresentar um panorama da atuação profissional de iluminação aplicada à arquitetura.

\section{Bloco 1 de perguntas: análise e discussão dos resultados ${ }^{14} e$ caracterização da amostra}

Após identificar os questionários passíveis de análise, a fase seguinte examinou todos as respostas do bloco 1 de perguntas e caracterizou a amostra, auxiliada pelas tabelas 2, 3, 4, 5 e 6. Na Tabela 2, nota-se que arquitetos têm

A partir de estudos de casos com lighting designers, Toledo (2008) apresentou problemas enfrentados na realidade dos projetos de iluminação. Alguns deles foram usados nas alternativas.

14 Houve redução de uma casa decimal dos números percentuais das tabelas 3, 5 e 6 (arredondamento de valores). 
participação significativa na produção de projetos de iluminação. Em segundo lugar figuram os designers, com 17 participantes.

Tabela 2: Colaboradores em categorias de especialidade: arquitetos; engenheiros e tecnólogos; desenhistas; designers; estagiários; outros

\begin{tabular}{lcc}
\multicolumn{1}{c}{ Profissão e/ou cargo } & Número absoluto & Média por escritório \\
\hline arquitetos & 45 & 1,73 \\
\hline engenheiros e tecnólogos & 10 & 0,38 \\
\hline desenhistas & 9 & 0,34 \\
\hline designers & 17 & 0,65 \\
\hline estagiários & 19 & 0,73 \\
\hline outros & 34 & 1,31 \\
\hline
\end{tabular}

Fonte: Elaborada pelos autores

Assim, é possível inferir que essa especialidade, apesar de não ser exclusiva de arquitetos, é uma importante área de atuação desses profissionais. Com relação à divisão geográfica, nota-se que a maioria absoluta dos profissionais que dedicam $80 \%$ ou mais das suas atividades a projetos de iluminação estão na região Sul e Sudeste, mais especificamente 88,4\%, conforme a Tabela 3. Esse dado se assemelha aos resultados da divisão demográfica de arquitetos e urbanistas nessas mesmas regiões, 76,41\%, identificado pelo censo realizado pelo Conselho de Arquitetura e Urbanismo do Brasil (2012).

Foi perguntado quais eram as principais tipologias arquitetônicas que demandam projetos de iluminação. O destaque na Tabela 4 apresenta as principais tipologias que compõem o portfólio de projetos, seis respondentes destacaram que projetos corporativos são o produto principal dos seus escritórios. Nota-se que a função desses espaços tem valor comercial associado ao seu produto ou serviço. Outro aspecto que demonstra que esses ambientes são mais cuidadosamente pensados é que códigos, normas e legislações são mais exigentes em ambientes de acesso público e destinados a um maior volume de pessoas; assim, isso também se transfere para as exigências sobre qualidade da iluminação (Figura 1) (JONES; MILLER; ILLUMINATING ENGINEERING SOCIETY OF NORTH AMERICA, 2008).

A maioria dos respondentes faz parte de escritórios de pequeno e médio porte (Tabela 5); apesar disso, mais de 80\% têm o seu chefe com experiência alta ou que são experts no assunto, com 20 anos ou mais de atuação na área (Tabela 6). Esses dados demonstram que os projetos são conduzidos principalmente por escritórios de até dez funcionários, mas os escritórios possuem em sua equipe projetistas experientes na área.

Tabela 3: Divisão da amostra por região geográfica

\begin{tabular}{ccc}
\hline Regiões do Brasil & Número absoluto & (\%) \\
\hline Centro-Oeste & 0 & $0,0 \%$ \\
\hline Nordeste & 0 & $0,0 \%$ \\
\hline Norte & 3 & $11,5 \%$ \\
\hline Sul & 5 & $19,2 \%$ \\
\hline Sudeste & 18 & $69,2 \%$ \\
\hline Total de respostas & 26 & $100 \%$ \\
\hline
\end{tabular}

Fonte: Elaborada pelos autores

Tabela 4: Tipologia arquitetônica mais frequente nos serviços prestados

\begin{tabular}{|c|c|}
\hline Tipologia & Quantidade \\
\hline corporativo & 6 \\
\hline comercial & 5 \\
\hline educacional & 5 \\
\hline institucional e/ou público & 4 \\
\hline hotelaria & 3 \\
\hline residencial & 3 \\
\hline Total de respostas & 26 \\
\hline
\end{tabular}

Fonte: Elaborada pelos autores 
Tabela 5: Classificação do escritório quanto ao tamanho

\begin{tabular}{cccccc}
\hline Número de funcionários & Categoria (porte) & Número absoluto & (\%) \\
\hline 1 a 3 & Pequeno & 9 & $34,6 \%$ \\
\hline 4 a 10 & Médio & 13 & $50,0 \%$ \\
\hline mais de 11 & Grande & 4 & $15,4 \%$ \\
\hline \multicolumn{2}{c}{ Total de respostas } & 26 & $100 \%$ \\
\hline
\end{tabular}

Fonte: Elaborada pelos autores

Tabela 6: Classificação do escritório com relação à experiência do chefe em anos

\begin{tabular}{ccccc}
\hline Tempo de atuação do chefe na área & Categoria & Número Absoluto & (\%) \\
\hline 2 a 5 anos & Mínima & 2 & $7,7 \%$ \\
\hline 6 a 10 anos & Pouca & 2 & $7,7 \%$ \\
\hline 11 a 20 anos & Alta & 9 & $34,6 \%$ \\
\hline Mais de 20 anos & Expert & 13 & $50,0 \%$ \\
\hline Total de respostas & & 26 & $100 \%$ \\
\hline
\end{tabular}

Fonte: Elaborada pelos autores

\section{Bloco 2 de perguntas: processo de projeto na rotina do escritório - análise e discussão dos resultados}

\section{Etapas de projeto - análise e discussão dos resultados}

Esse tópico analisa e discute os resultados apresentados no Gráfico 1, que representa as etapas de projeto desenvolvidas pelos respondentes. Assim o item mais destacável na análise dos resultados foi “d) estudo preliminar e anteprojeto", pois 96,2\% dos projetistas executam essa fase. Essa foi a única etapa em que a alternativa negativa não recebeu qualquer marcação, o que denota prioridade na etapa d) mais do que nas etapas a), b) e c). Howard Brandston ${ }^{15}$, no livro de sua autoria, destaca que o seu primeiro passo de projeto é "obter o programa do cliente" para fazer análises objetivas e subjetivas; depois, é realizado um "estudo preliminar" para desenvolver o conceito (BRANDSTON, 2010). Dessa maneira, assim como em nossa amostra, Brandston (2010) aprofunda suas atividades no estudo preliminar.

Gráfico 1: Fases desenvolvidas no processo de projeto

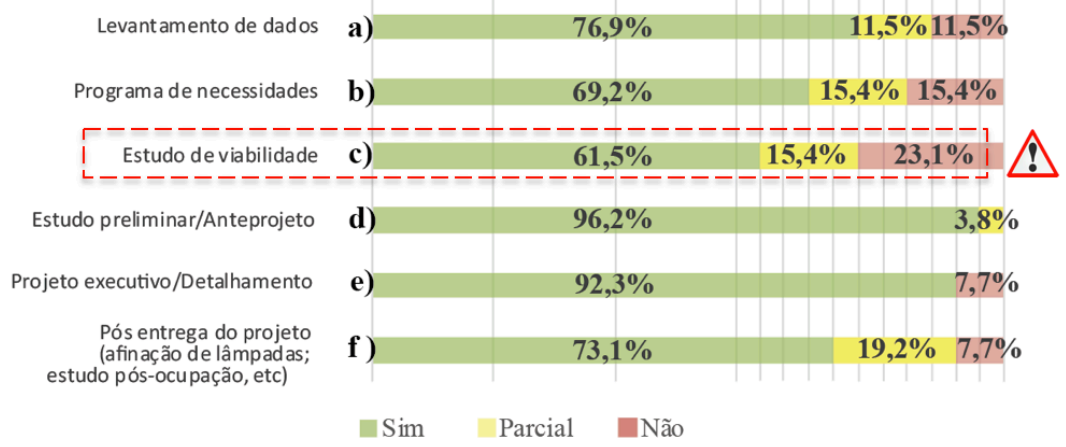

Fonte: Elaborado pelos autores

Ambos nossa amostra e o lighting designer seguem uma sequência diferente da descrita na NBR 13532. Tendo em vista que, em geral, os projetistas de iluminação são contatados para edificação existente ou quando o estudo preliminar da arquitetura já está avançado, é compreensível que as informações do contratante possam ser suficientes para o designer de iluminação iniciar o estudo preliminar. No campo de comentários ${ }^{16}$ desta

\footnotetext{
Premiado lighting designer americano.

16 Outros comentários da questão "Etapas de projeto": briefing; controlamos toda a parte inteligente da casa: automação, som, elétrica, painéis solares; revisão e acompanhamento; consultorias técnicas; etapas de-
} 
questão, um dos projetistas destacou o briefing como fase, demonstrando que no caso do projeto de iluminação, o levantamento de dados pode se dar a partir de uma conversa com o contratante.

Ainda que haja um grande volume de informações disponíveis aos projetistas, faz-se necessária a realização da análise da viabilidade e a elaboração de pré-orçamentos do projeto de iluminação. Contudo, a etapa “c) estudo de viabilidade” é executada apenas por 55\% dos entrevistados. Assim, é pertinente a adoção de questionamentos baseados na pesquisa de Morais, Granja e Ruschel (2015) para justificar a não realização de estudo de viabilidade:

1) é possível que o projetista siga um orçamento já estabelecido pelo cliente e, assim, tenha que usar conceitos de target costing ${ }^{17}$;

2) no campo "comentários” do tópico a seguir (ferramentas utilizadas), não é citado o uso de nenhuma ferramenta BIM $^{18}$ que possa auxiliar na elaboração de quantitativos;

Assim, a análise da viabilidade do projeto poderia ser medida não apenas com uma etapa antes do estudo preliminar, mas também através de ferramentas durante o processo, como com o uso de recursos existentes no software DIALux.

Ferramentas utilizadas no processo de projeto - análise e discussão dos resultados

A partir da observação do Gráfico 2, nota-se que a maioria do público entrevistado, quase 80\%, utiliza “d) checklists" e “c) códigos, normas [...]". Também foi identificado que cada projetista/escritório utiliza pelo menos uma ferramenta de auxílio ao processo de projeto. O campo "comentários" recebeu sete respostas. A observação mais recorrente foi "software de cálculo luminotécnico"19 (foi citado o DIALux para simular iluminação, mas a maioria apenas citou o uso de software específico de iluminação). Os outros comentários destacaram alternativas não contempladas no questionário, salientando a importância de ferramentas específicas de auxílio ao projeto, como croquis/mão livre, técnicas gráficas em software editor de imagens (exemplo: Photoshop), catálogos técnicos, AutoCad, DIALux. Recursos computacionais influenciam o resultado do projeto em diferentes níveis (CELANI; GODOI; RODRIGUES, 2007; MORAIS; GRANJA; RUSCHEL, 2015).

Gráfico 2: Ferramentas utilizadas no processo de projeto

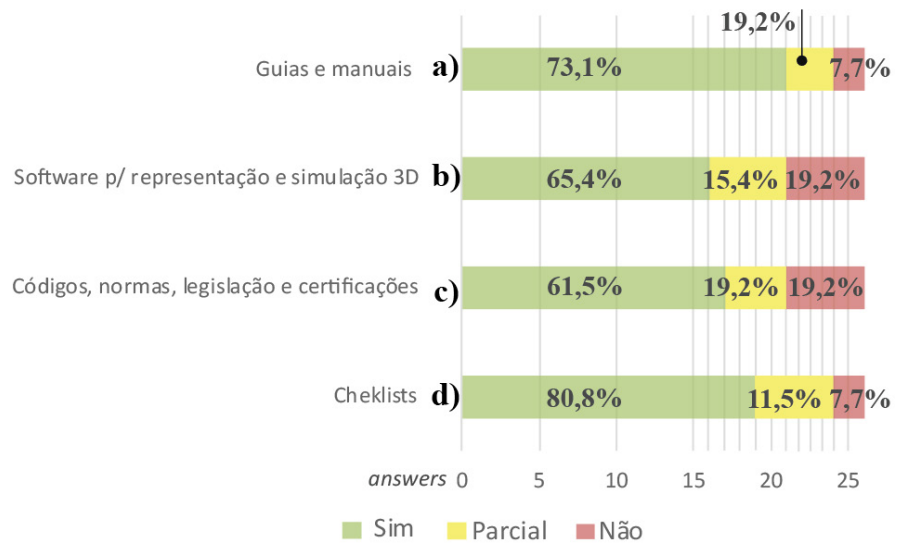

Fonte: Elaborado pelos autores

pendem do tipo de contrato, se há ou não outro profissional envolvido etc.; nem todas as etapas fazem parte de todos os contratos; medições de níveis de iluminamento/avaliação de iluminação existente com emissão de relatório; pesquisas relacionadas a processos físicos, químicos e biológicos; acompanhamento de concorrências de equipamentos (parcial).

Custeio-meta.

Modelagem da Informação da Construção; BIM, do inglês, Building Information Modeling

Texto idêntico comentado por outros três profissionais. Portanto, quatro profissionais no total destacaram o uso de software de cálculo de iluminação. 
Esse item do questionário baseou-se na literatura sobre qualidade de iluminação com o propósito de identificar as variáveis de projeto utilizadas na prática por projetistas de iluminação (JONES; MILLER; ILLUMINATING ENGINEERING SOCIETY OF NORTH AMERICA, 2008). A seguir, temos os resultados referentes aos tópicos considerados no momento de desenvolvimento do projeto. O Gráfico 3 apresenta $11^{20}$ tópicos, sete deles, a), b), c), d), g), h) e i), são considerados por mais de $80 \%$ dos entrevistados. Essa coincidência é alta, especialmente se partirmos do pressuposto que existem projetos de diferentes escopos, e que alguns profissionais prestam serviços apenas em algumas fases. É destacável o item d), no qual visibilidade e conforto visual são considerados por todos os projetistas consultados, portanto o tópico é essencial a um projeto de iluminação, segundo os entrevistados.

Destacam-se também os tópicos “a) estética”, “b) forma, estilo e composição" e “c) desempenho de tarefas”, pois, além de serem considerados por mais de $90 \%$ dos respondentes, não receberam respostas negativas. Em oposição, o item menos considerado foi "k) manutenção e operação dos equipamentos/ sistemas especificados”, o que sugere que sistemas de iluminação podem sofrer problemas na fase de manutenção por falta de planejamento.

Gráfico 3: Variáveis de projeto consideradas para o desenvolvimento de projetos de iluminação

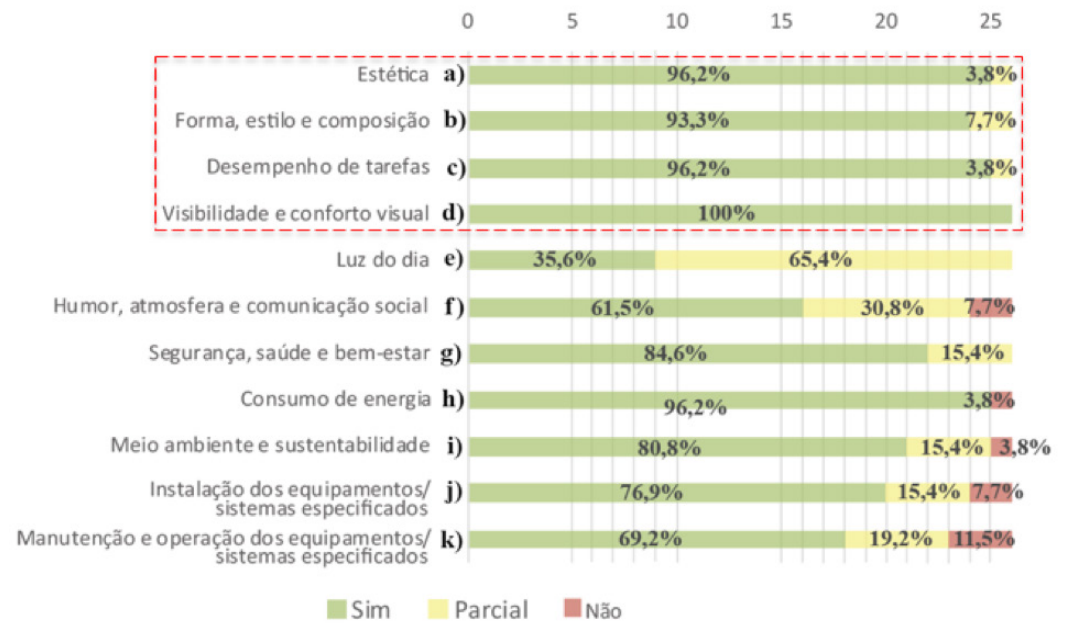

Fonte: Elaborado pelos autores

O campo de comentários recebeu informações que podem ser relacionadas com algumas variáveis de projeto. Um dos comentários destacou "diálogo com o partido arquitetônico", que pode ser relacionado à opção "b) forma, estilo e composição"; já o comentário "projetos são baseados principalmente nas normas técnicas e de segurança” se refere ao tópico "g) segurança, saúde e bem-estar"; e um terceiro reforçou que "probabilidade de ofuscamento é considerado no item visibilidade e conforto visual", referindo-se ao tópico “d) visibilidade e conforto visual".

\section{Dificuldades enfrentadas pelos projetistas - análise e discussão dos resultados}

Identificar dificuldades pode servir como meio de compreensão para alguns problemas. Em virtude disso, foi questionado quais dificuldades são enfrentadas na rotina dos projetistas. Conforme o Gráfico 4, em linhas gerais,

${ }_{20}$ Os assuntos correlatos, como por exemplo, forma/estilo/composição, foram reunidos em um tópico, pois estão no mesmo círculo do diagrama da IES, Figura 1. 
o problema que mais recebeu “i) sempre” foi “c) projeto de iluminação é contratado em fases avançadas do projeto de arquitetura”, que, somado à alternativa “ii) frequentemente", dá um total de 80,8\% de incidência. Essa alternativa demonstra prejuízo tanto no desenvolvimento compartilhado no momento projetual da arquitetura como no uso de recursos de iluminação natural. Isso tende a limitar o trabalho do especialista em iluminação, principalmente ao usar recursos de iluminação artificial.

Outros problemas recorrentes foram “a) interferências/alterações não planejadas" e "b) recursos insuficientes para o escopo do projeto". A soma da incidência das alternativas "i) sempre" e "ii) frequentemente" também, nesses dois casos, é maior que $80 \%$. Esse dado demonstra que pode haver falta de planejamento por parte do contratante ou, ainda, do lighting designer que é o prestador de serviço. É possível relacionar essa falta de planejamento aos resultados da etapa "c) estudo de viabilidade" do item "Etapas de projeto" (Gráfico 1), pois este só é desenvolvido por $61,5 \%$ dos projetistas, o que, no caso, se refere a 16 projetistas ${ }^{21}$, dos quais seis também marcaram que “i) sempre” ou “ii) frequentemente” "b) os recursos são insuficientes para o escopo do projeto" (Gráfico 4). Ainda assim, as dificuldades a), b) e c) são enfrentadas “i) sempre” ou "ii) frequentemente" por pelo menos 20 dos 26 respondentes. Isso demonstra que, possivelmente, outros aspectos causam os problemas enfrentados pelos profissionais e necessitam ser levantados em pesquisas futuras.

Gráfico 4: Dificuldades enfrentadas na rotina dos escritórios

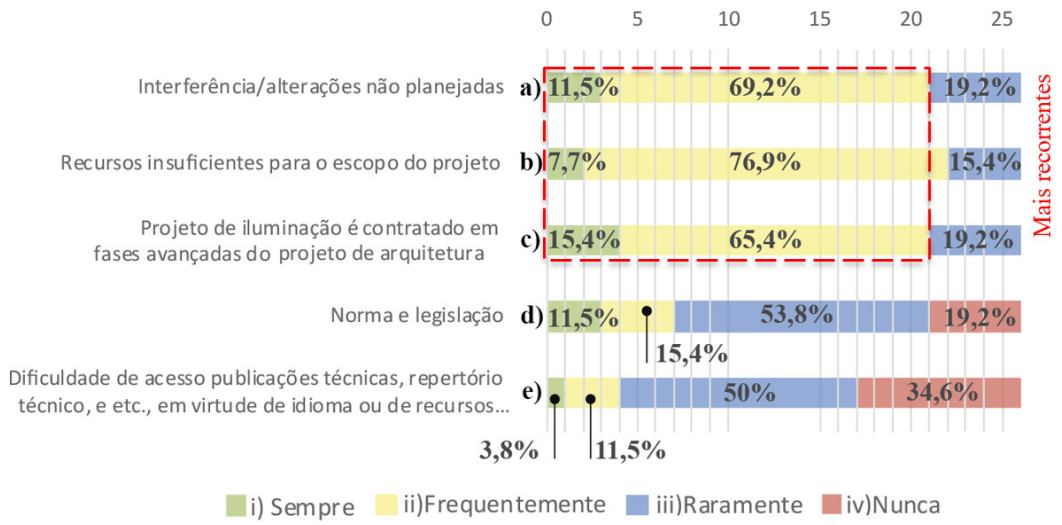

Fonte: Elaborado pelos autores

\section{CONSIDERAÇÕES FINAIS}

O estudo do processo de projeto é fundamental para que se compreenda a relação dele com as soluções de iluminação executadas. Neste artigo, o processo de projeto de iluminação foi dividido por meio dos elementos que o compõem. Assim, a interpretação de cada parte ajudou a compreender como o todo é desenvolvido, inclusive identificando lacunas. A divisão também permitiu decompor o processo de projeto em questões. Dessa forma, por meio de questionário eletrônico, foi possível consultar lighting designers, os grandes responsáveis por escolher as ferramentas e desenvolver soluções de iluminação aplicadas à arquitetura.

A apreciação dos resultados em termos gerais, mantendo em mente a metodologia utilizada, demonstrou que arquitetos têm grande participação nesse mercado. Suas atividades profissionais são, principalmente, nas regiões mais industrializadas, isto é, no Sudeste e no Sul do país. Os profissionais que se dedicam ao mercado de iluminação têm experiência alta (em anos), e seus escritórios são compostos de até dez funcionários. Nota-se que os especialistas 
em iluminação possuem vasta experiência na área e atuam principalmente em escritórios de pequeno e médio porte. Seus portfólios são compostos, principalmente, de arquitetura corporativa, comercial e educacional, o que demonstra que a valorização desse especialista está principalmente associada a ambientes em que a qualidade do espaço agrega valor a produtos e serviços. Assim, é possível inferir que escritórios de iluminação são focados, que seus projetistas-chefe são experientes, e que seus clientes necessitam de projetos com qualidade e segurança para acesso ao público.

Com relação às fases de projeto e seguindo a ordem preconizada pela literatura, as primeiras fases não acontecem em todos os casos. As fases "estudo preliminar" e "anteprojeto" sempre são executadas, o que evidencia maior complexidade delas e a necessidade de mapeamento para entendimento das suas subetapas e ações. Em relação às ferramentas de apoio, todos os profissionais usam pelo menos uma.

A literatura sobre processo de projeto em iluminação não se aprofunda nesse item, o que demonstra uma lacuna a ser preenchida sobre quais ferramentas são utilizadas em cada fase e para auxiliar quais atividades. Projetos de iluminação são contratados em fases avançadas do projeto de arquitetura, o que gera prejuízo na escolha de soluções que aproveitem de forma inteligente a luz natural, influenciando o uso melhor de recursos de eficiência energética em geral, e limitando, assim, o trabalho do especialista durante o projeto de iluminação artificial. Em relação a outras dificuldades que os projetistas enfrentam, é fundamental que em pesquisas futuras se identifiquem as suas causas, e ferramentas e estratégias para evitá-las.

Em pesquisas futuras, com amostra ampliada, será necessário abordar questões específicas de iluminação natural no processo de projeto, tais como uso de equipamentos e conceitos de geometria solar. Também se faz necessário investigar mais a fundo questões referentes ao uso de ferramentas de apoio, especialmente ferramentas computacionais de simulação - se há facilidade de acesso para os profissionais, quais são as mais utilizadas, dentre outros aspectos. Por fim, é destacável que a pesquisa, apesar de embrionária sobre o assunto, permitiu caracterizar o processo de projeto em iluminação por meio de aspectos até então pouco discutidos na literatura nacional. Por se tratar de uma área nova dentro da arquitetura - surgiu por volta da década de 1950 (NEUMANN, 2010) -, a prática projetual de iluminação foi pouco discutida e é pouco registrada. Dessa forma, é necessário ampliar as pesquisas nesse tema e as fronteiras do conhecimento sobre qualidade da iluminação na arquitetura.

\section{AGRADECIMENTOS}

À Fundação de Amparo à Pesquisa do Estado de São Paulo (Fapesp) pela bolsa concedida, processo no 2017/05309-0.

\section{REFERÊNCIAS}

ABOUT LIGHTING design. International Association of Lighting Designers, Chicago, [201-?]. Disponível em: <https:// bit.ly/2v2cpfP>. Acesso em: 7 set 2015

ASSOCIAÇÃO BRASILEIRA DE ARQUITETOS DE ILUMINAÇÃO. Manual de escopo de projeto luminotécnico. São Paulo, 2000. Disponível em: <https://bit.ly/2GNfeCM>. Acesso em: 1 mar. 2017.

ASSOCIAÇÃO BRASILEIRA DE NORMAS TÉCNICAS. NBR 13532: elaboração de projetos de edificações: arquitetura. Rio de Janeiro, 1995.
NBR ISO/CIE 8995-1: iluminação de ambientes de trabalho. Rio de Janeiro, 2013. $B A B B I E, E$. Métodos de pesquisa de survey. Belo Horizonte: Editora UFMG, 1999.

BARON, R. A.; REA, M. S.; DANIELS, S. G. Effects of indoor lighting (illuminance and spectral distribution) on the performance of cognitive tasks and interpersonal behaviors: the potential mediating role of positive affect. Motivation and Emotion, Dordrecht, v. 16, n. 1, p. 1-33, mar. 1992. Disponível em: <https:// bit.ly/2HtvzOc>. Acesso em: 10 maio 2017. 
BOYCE, P. R.; SMET, K. A. G. LRT symposium "Better metrics for better lighting": a summary. Lighting Research \& Technology, Boston, v. 46, n. 6, p. 619-636, 2014. Disponível em: <https://bit.ly/2HqLc8X>. Acesso em: 10 maio 2017.

BRANDSTON, H. M. Aprender a ver: a essência do design da iluminação. São Paulo: De Maio, 2010

Lighting design: Armagedom está próximo. Revista Lume, São Paulo, n. 55, p. 116-117, 2012. Disponível em: <https://bit. Iy/2IJZsZTT>. Acesso em: 10 abr. 2018.

CELANI, G.; GODOI, G.; RODRIGUES, G. O processo de projeto arquitetônico mediado por computador: um estudo de caso com o Architectural Desktop. In: SIMPÓSIO NACIONAL DE GEOMETRIA DESCRITIVA E DESENHO TÉCNICO, 18., 2007, Curitiba. Resumos... Curitiba: UFPR, 2007.

CONSELHO DE ARQUITETURA E URBANISMO DO BRASIL. Censo dos Arquitetos e Urbanistas do Brasil. Brasília, 2012. Disponível em: <https://bit.ly/2J9p6Y3>. Acesso em: 13 mar. 2017.

DELIBERADOR, M. S. O processo de projeto de arquitetura escolar no estado de São Paulo: caracterização e possibilidades de intervenção. 2010. 254 f. Dissertação (Mestrado em Arquitetura, Tecnologia e Cidade) - Faculdade de Engenharia Civil, Arquitetura e Urbanismo, Universidade de Campinas, Campinas, 2010

DILAURA, D. L.; ILLUMINATING ENGINEERING SOCIETY OF NORTH AMERICA. The lighting handbook: reference and application. 10. ed. New York: Illuminating Engineering Society of North America, 2011

GÜNTHER, H. Como elaborar um questionário. Série: Planejamento de Pesquisa nas Ciências Sociais, Brasília, DF, n. 1, p. 1-15, 2003.

JONES, C.; MILLER, N.; ILLUMINATING ENGINEERING SOCIETY OF NORTH AMERICA. Light + design: a guide to designing quality lighting for people and buildings. New York: Illuminating Engineering Society of North America, 2008.
KOWALTOWSKI, D. C. C. K.; BIANCHI, G.; PETRECHE, J. R. D. A criatividade no processo de projeto. In: KOWALTOWSKI, D. C. C. K. et al. (Org.). 0 processo de projeto em arquitetura: da teoria à prática. São Paulo: Oficina de Textos, 2011. p. 21-56.

MORAIS, M.; GRANJA, A. D.; RUSCHEL, R. C. Restrições orçamentárias e entrega de valor: sinergias entre BIM e custeio-meta. Gestão e Tecnologia de Projetos, São Paulo, v. 10, n. 1, p. 7-27, ago. 2015. Disponível em: <https://bit. ly/2EBOhla>. Acesso em: 8 jan. 2018.

NEUMANN, D. The structure of light: Richard Kelly and the illumination of modern architecture. New York: Yale University Press, 2010.

OLIVEIRA, P. R. G. Cartilha informativa sobre lighting design. 2012. $18 \mathrm{f}$. Monografia (Pós-Graduação em Iluminação e Design de Interiores) - Instituto de Pós-Graduação, Londrina, 2012. Disponível em: <https://bit. Iy/2qnfJNy>. Acesso em: 1ำ mar. 2017.

REA, M. S.; ILLUMINATING ENGINEERING SOCIETY OF NORTH AMERICA. The IESNA lighting handbook: reference and application. 9. ed. New York: Illuminating Engineering Society of North America, 2000.

ROMANO, F. V. Modelo de referência para o gerenciamento do processo de projeto integrado de edificações. Gestão e Tecnologia de Projetos, São Paulo, v. 1, n. 1, p. 23-46, set. 2006. Disponível em: <https:// bit.ly/2v7PHTA>. Acesso em: 10 maio 2017.

TOLEDO, B. G. Integração de iluminação natural e artificial: métodos e guia prático para projeto luminotécnico. 2008. 190 f. Dissertação (Mestrado em Arquitetura e Urbanismo) - Faculdade de Arquitetura e Urbanismo, Universidade de Brasília, Brasília, 2008.

VOLPATO, G. L.; BARRETO, R. E.; Estatística sem dor!!! Botucatu: Best Writing, 2016.

WANG, N.; BOUBEKRI, M. Design recommendations based on cognitive, mood and preference assessments in a sunlit workspace. Lighting Research \& Technology, Boston, v. 43, n. 1, p. 55-72, 3 jan. 2011. Disponível em: <https://bit.ly/2GPykrP>. Acesso em: 10 maio 2017.
Fernanda Brito Bandeira fbritobandeira@gmail.com

Paulo Sergio Scarazzato pasezato@usp.br 